\title{
Phylogenetic analysis of Saccharothrix and related taxa: proposal for Actinosynnemataceae fam. nov.
}

\author{
David P. Labeda ${ }^{1}$ and Reiner M. Kroppenstedt ${ }^{2}$
}

\begin{abstract}
Author for correspondence: David P. Labeda. Tel: +1 309681 6397. Fax: +1 3096816672. e-mail: dlabeda@sunca.ncaur.usda.gov
\end{abstract}

\author{
1 Microbial Properties \\ Research Unit, National \\ Center for Agricultural \\ Utilization Research, \\ Agricultural Research \\ Service, US Department of \\ Agriculture, $1815 \mathrm{~N}$. \\ University Street, Peoria, \\ IL 61604, USA \\ 2 DSMZ-Germany Collection \\ of Microorganisms and \\ Cell Cultures, \\ Braunschweig, Germany
}

\begin{abstract}
Partial sequences for 165 rDNA were determined for strains of the genus Saccharothrix, including most described species, as well as strains of the described species of the related genera Kutzneria, Actinokineospora and Actinosynnema. These were aligned with published sequences for other species of these genera, as well as those of the genera 'Actinoalloteichus', 'Asiosporangium', Lentzea, Kutzneria, Streptoalloteichus and representative taxa from other actinomycete families. Phylogenetic analysis of the sequence data showed that species of the genera Actinokineospora, Actinosynnema, Lentzea and Saccharothrix are members of the same clade, and distinct from the Pseudonocardiaceae. It is proposed that a new family be created within the class Actinobacteria for these genera, to be called the Actinosynnemataceae on the basis of the oldest described genus within this family, Actinosynnema Hasegawa et al. The chemotaxonomic properties of all the genera to be placed within the new family have similar cell wall type (type III), whole-cell sugars (generally galactose although mannose and rhamnose may be present), phospholipid type (PII) and menaquinones [MK-9 $\left(\mathrm{H}_{4}\right)$ predominant].
\end{abstract}

Keywords: Saccharothrix, actinomycetes, Actinosynnemataceae fam. nov.

\section{INTRODUCTION}

The genus Saccharothrix was described (Labeda et al., 1984) to accommodate actinomycete strains that morphologically resemble the genus Nocardiopsis, but that can be chemotaxonomically differentiated from members of this genus based on type III cell wall chemistry (meso-diaminopimelic acid, meso-DAP), rhamnose and galactose as diagnostic whole-cell sugars, a type PII phospholipid pattern (phosphatidylethanolamine as key diagnostic phospholipid), and presence of MK$9\left(\mathrm{H}_{4}\right)$ as the predominant menaquinone. The actual phylogenetic position of this genus has not been certain, although it was suggested by Warwick et al. (1994), on the basis of a phylogenetic study of $16 \mathrm{~S}$ rRNA sequences, that this genus should be placed phylogenetically with the Pseudonocardiaceae. In the recent proposal for the hierarchic classification of actinomycete taxa in the new class Actinobacteria

Abbreviation: DAP, diaminopimelic acid.

The GenBank accession numbers for the 16S rDNA sequences determined in this paper are AF114797-AF114815.
(Stackebrandt et al., 1997), members of the genus Saccharothrix are again loosely grouped with the Pseudonocardiaceae. Yassin et al. (1995) noted the close phylogenetic relationship of their new genus Lentzea to members of the genera Actinosynnema, Kutzneria and Saccharothrix. In order to clarify the phylogenetic position of this genus, as well as to study its phylogenetic continuity, 16S rDNA sequence data were determined for representative type strains of species of Saccharothrix and allied genera selected from the ARS Culture Collection.

\section{METHODS}

Strains, cultivation and maintenance. All strains included in this study are held in the ARS Culture Collection (NRRL), National Center for Agricultural Utilization Research, Peoria, IL, USA. The strains selected for this are shown in Table 1. Primary storage of strains is as lyophilized ampules of mycelial and spore suspensions in sterile beef serum held at $4{ }^{\circ} \mathrm{C}$. Working stock cultures were maintained on slants of ATCC Medium No. 172 (Cote et al., 1984) and stored at $4{ }^{\circ} \mathrm{C}$ until needed. Biomass for extraction of DNA was grown as $7 \mathrm{~d}$ streak cultures on ATCC Medium 172 agar plates. 
Table 1. Strains for which $16 \mathrm{~S}$ rDNA sequence data were determined in this study

\begin{tabular}{|c|c|}
\hline Strain & GenBank no. \\
\hline Actinokineospora diospyrosa NRRL B-24047 $7^{\mathrm{T}}\left(=\mathrm{IFO} 15665^{\mathrm{T}}\right)$ & AF114797 \\
\hline Actinokineospora globicatena NRRL B-24048 ${ }^{\mathrm{T}}\left(=\mathrm{IFO} 15664^{\mathrm{T}}\right)$ & AF114798 \\
\hline Actinokineospora inagensis NRRL B-24050 $\left(=\mathrm{IFO} 15663^{\mathrm{T}}\right)$ & AF114799 \\
\hline Actinokineospora riparia NRRL B-16432 ${ }^{\mathrm{T}}$ & AF114802 \\
\hline Actinosynnema pretiosum subsp. pretiosum NRRL B-16060 ${ }^{\mathrm{T}}$ & AF114800 \\
\hline Kutzneria kofuensis NRRL B-24061 ${ }^{\mathrm{T}}\left(=\mathrm{JCM} 3157^{\mathrm{T}}\right)$ & AF114801 \\
\hline Saccharothrix aerocolonigenes NRRL B-3298 & AF114804 \\
\hline Saccharothrix australiensis NRRL $11239^{\mathrm{T}}$ & AF114803 \\
\hline Saccharothrix coeruleofusca NRRL B-16115 ${ }^{\mathrm{T}}\left(=\right.$ ATCC $\left.35108^{\mathrm{T}}=\mathrm{DSM} 43679^{\mathrm{T}}\right)$ & AF114805 \\
\hline Saccharothrix cryophilis NRRL B-16238 ${ }^{\mathrm{T}}$ & AF114806 \\
\hline Saccharothrix espanaensis NRRL $15764^{\mathrm{T}}$ & AF114807 \\
\hline Saccharothrix flava NRRL B-16131 ${ }^{\mathrm{T}}\left(=\mathrm{ATCC} 29533^{\mathrm{T}}=\mathrm{DSM} 43885^{\mathrm{T}}\right)$ & AF114808 \\
\hline Saccharothrix longispora NRRL B-16116 $\left(=\right.$ ATCC $\left.35109^{\mathrm{T}}=\mathrm{DSM} 43749^{\mathrm{T}}\right)$ & AF114809 \\
\hline Saccharothrix syringae NRRL B-16468 ${ }^{\mathrm{T}}\left(=\mathrm{DSM} 43886^{\mathrm{T}}\right)$ & AF114812 \\
\hline Saccharothrix texasensis NRRL B-16107 & AF114815 \\
\hline Saccharothrix texasensis NRRL B-16134 ${ }^{\mathrm{T}}$ & AF114814 \\
\hline Saccharothrix waywayandensis NRRL B-16159 & AF114813 \\
\hline Saccharothrix species NRRL B-16108 & AF114810 \\
\hline Saccharothrix species NRRL B-16133 & AF114811 \\
\hline
\end{tabular}

Chemotaxonomic analysis. The chemotaxonomic profile of Lentzea albidocapillata was determined using previously described methods (Grund \& Kroppenstedt, 1989) for menaquinones, fatty acids and whole-cell sugars.

DNA extraction. Genomic DNA was isolated and purified by a modification of the procedure of Rainey et al. (1996). Cells scraped from solid growth media (1-2 loopfuls) were placed in a $1.5 \mathrm{ml}$ microfuge tube with a small amount of $0.1 \mathrm{~mm}$ zirconia/silica beads (Biospec Products) and were ground with a conical disposable pestle (Kontes Glass Company). The homogenate was suspended in $400 \mu \mathrm{l}$ saline-EDTA buffer (150 mM NaCl, $10 \mathrm{mM}$ EDTA; pH 8.0), $10 \mu \mathrm{l} 1 \%$ $(\mathrm{w} / \mathrm{v})$ proteinase $\mathrm{K}$ and $10 \mu 125 \%(\mathrm{w} / \mathrm{v})$ SDS was added, mixed and incubated at $55-60{ }^{\circ} \mathrm{C}$ for $10 \mathrm{~min}$. The resulting preparation was extracted sequentially with an equal volume of phenol, and an equal volume of chloroform. DNA was recovered from the aqueous phase by using a Prep-A-Gene kit (Bio-Rad). The purified DNA was eluted from the binding matrix in $30 \mu$ sterile distilled water.

Amplification and direct sequencing of the 16S rRNA gene. The 16S rDNA was amplified by the PCR according to the method of Rainey et al. (1996) using the primers $27 \mathrm{f}$ (GAGTTTGATCCTGGCTCAG) and 1525r (AGAAAGGAGGTGATCCAGCC). PCR products were purified and concentrated using a Gene-Clean II kit (Bio 101) and were eluted into $30 \mu \mathrm{l}$ sterile distilled water. The sequencing reactions were performed with a PRISM Ready-Reaction DyeDeoxy terminator cycle sequencing kit by using AmpliTaq FS (Applied Biosystems) and a Perkin-Elmer Cetus model 2400 thermal cycler according to the protocol and thermal profile recommended by Applied Biosystems. The sequencing primers used were: $343 \mathrm{r}$ (CTGCTGCCTCCCGTA), 357f (TACGGGAGGCAGCAG), 519r [G(T/A)ATTACCGCGGC(T/G)GCTG], 536f [CAGC(C/A)GCCGCGGTAAT(T/A)C], 803f (ATTAGATACCCTGGTAG), 907r (CCGTCAATTCATTTGAGTTT), 1114f (GCAACGAGCGCAACCC) and 1385r [CGGTGTGT(A/G)-
CAAGGCCC]. Sequencing reaction mixtures were purified as recommended by Applied Biosystems and were electrophoresed on a $6 \%(\mathrm{w} / \mathrm{v})$ polyacrylamide sequencing gel for $9 \mathrm{~h}$ using either a $373 \mathrm{~A}$ or 377 model automated DNA sequencer (Applied Biosystems).

Phylogenetic analysis. The $16 \mathrm{~S}$ rDNA sequences obtained in this study were manually aligned with actinomycete reference sequences obtained from the Ribosomal Database Project (Maidak et al., 1994) and GenBank. Many of the reference sequences obtained from the databases were partial sequences and thus the data set used for analysis consisted of the sequences generated in this study and actinomycete reference sequences contained information for 1384 nucleotide positions. The programs contained in the PHYLIP package of Felsenstein (1993) were used to calculate evolutionary distances by the method of Kimura (1980), and linkages by the neighbour-joining method of Saitou \& Nei (1987). The topographies of the trees resulting from these analyses were evaluated by bootstrap analysis of the data with 100 resamplings. The sequences were also subjected to likelihood analysis using fastDNAml (Olsen et al., 1994) and PAUP 3.1 (Swofford, 1993) was used for parsimony analysis. Evolutionary trees were displayed and printed using version 1.5 of the TREEVIEW program of Page (1996).

Nucleotide sequence accession numbers. The 16S rDNA sequences determined in this study have been deposited in the GenBank database under the accession numbers shown in Table 1. The accession numbers for the sequences of the strains used as representatives of the main actinomycete groups are as follows: 'Actinoalloteichus cyanogriseus' IFO 14455, AB006178; Actinomadura kijaniata DSM 43764 $\left({ }^{\mathrm{T}}=\right.$ type strain), X97890; Actinomadura madurae DSM 43067 ${ }^{\mathrm{T}}$ X97889; Actinoplanes philippinensis DSM 43019 X93187; Actinosynnema mirum DSM 43827 ${ }^{\mathrm{T}}$, X84447; Amycolatopsis mediterranei ATCC $13685^{\mathrm{T}}$ (= DSM $43304^{\mathrm{T}}$ $=\mathrm{IFO} 13415^{\mathrm{T}}=\mathrm{IMET}$ 7651 ${ }^{\mathrm{T}}$ ), X76957; Amycolatopsis methanolica NCIB 11946 ${ }^{\mathrm{T}}$, X54274; Amycolatopsis orientalis 
DSM 40040 ${ }^{\mathrm{T}}$ (= NCIMB 9378 $)$, X76958; Arthrobacter globiformis DSM 20124 $\quad\left(=\right.$ ATCC $8010^{\mathrm{T}}=\mathrm{NCIMB}$ 8907'), M23411; 'Asiosporangium albidum' IFO 16102, AB006176; Atopobium minutum NCFB 2751 ${ }^{\mathrm{T}}(=\mathrm{DSM}$ $20586^{\mathrm{T}}=$ ATCC $33267^{\mathrm{T}}=$ VPI $9428^{\mathrm{T}}$ ), X67148; Bifidobacterium bifidum ATCC $29521^{\mathrm{T}}$ (= DSM 20456 ${ }^{\mathrm{T}}$ ), M38018; Dactylosporangium aurantiacum DSM 43157 ${ }^{\mathrm{T}}$, X93191; Kibdelosporangium aridum subsp. aridum ATCC 39323 ${ }^{\mathrm{T}}$, X53191; Kutzneria viridogrisea DSM 43850 ${ }^{\mathrm{T}}$ (= ATCC $\left.25242^{\mathrm{T}}\right)$, X70429; Lentzea albidocapillata DSM 44073 ${ }^{\mathrm{T}}$, X84321; Microbacterium lacticum IFO $14135^{\mathrm{T}}$ (= NCIMB $8540^{\mathrm{T}}=\mathrm{ATCC} \quad 8180^{\mathrm{T}}=\mathrm{DSM} \quad 20427^{\mathrm{T}}=\mathrm{NCFB} \quad 747^{\mathrm{T}}$ ), D21343; Microlunatus phosphovorus, JCM 9379 ${ }^{\mathrm{T}}$, D26169; Micromonospora chalcea DSM 43026 ${ }^{\mathrm{T}}$, X92594; Microtetraspora glauca DSM 43311 ${ }^{\mathrm{T}}$, X97891; Nonomuria salmonea DSM 43678 ${ }^{\mathrm{T}}$, X97892; Mycobacterium tuberculosis, NCTC 7416 ${ }^{\mathrm{T}}$, X58890; Nocardia asteroides ATCC $19247^{\mathrm{T}}$, Z36934; Nocardioides albus DSM 43109 ${ }^{\mathrm{T}}$ (= ATCC 27980), X53211; Nocardiopsis dassonvillei DSM 43111' , X97886; Propionibacterium freudenreichii subsp. freudenreichii DSM $20271^{\mathrm{T}}\left(=\right.$ ATCC $\left.6207^{\mathrm{T}}=\mathrm{NCTC} 10470^{\mathrm{T}}=\mathrm{NCIB} 5959^{\mathrm{T}}\right)$, X53217; Pseudonocardia alni VKM AC901 ${ }^{\mathrm{T}}$, X76954; Pseudonocardia halophobica DSM 43089 ${ }^{\mathrm{T}}$, Z14111; Pseudonocardia petroleophila ATCC $15777^{\mathrm{T}}$ (= DSM 43193 ${ }^{\mathrm{T}}$ ), X80596; Saccharomonospora azurea IFO 14651 ${ }^{\mathrm{T}}$, Z38017; 'Saccharomonospora caesia' INMI 19125', X76960; Saccharomonospora cyanea IFO 14841 ${ }^{\mathrm{T}}$, Z38018; Saccharomonospora glauca DSM 43769 ${ }^{\mathrm{T}}$, Z38003; Saccharomonospora viridis Goodfellow SB-33, Z38005; Saccharopolyspora gregorii NCIMB 12823 ${ }^{\mathrm{T}}$, X76962; Saccharopolyspora hirsuta ATCC 27875 $(=$ NCIB 11079 $)$, M20388; Saccharothrix mutabilis subsp. capreolus DSM 40225 X76965; Saccharothrix mutabilis subsp. mutabilis DSM 43853' ${ }^{\mathrm{T}}$ X76966; Sporichthya polymorpha DSM 46113, X72377; Streptoalloteichus hindustanus IFO $15115^{\mathrm{T}}$, D85497; Streptomyces ambofaciens ATCC 23877 ${ }^{\mathrm{T}}$, M27245; Streptomyces griseus KCTC 9080 ${ }^{\mathrm{T}}$, X61478; Streptosporangium longisporum DSM 43180 ${ }^{\mathrm{T}}$, X89944; Streptosporangium roseum DSM 43021 ${ }^{\mathrm{T}}$, X89947; Thermocrispum agreste DSM $44070^{\mathrm{T}}$, X79183; Thermocrispum municipale DSM 44069 ${ }^{\mathrm{T}}$, X79184; Thermomonspora curvata DSM 43183' ${ }^{\mathrm{T}}$ X97893.

\section{RESULTS}

\section{Phylogenetic analyses}

Almost complete $16 \mathrm{~S}$ rDNA sequences were determined for type strains of the genera Actinokineospora, Kutzneria and Saccharothrix for which these data had not been previously reported. In addition, similar data were determined for Saccharothrix australiensis NRRL 11239 ${ }^{\mathrm{T}}$, Saccharothrix coeruleofusca NRRL B-16115 ${ }^{\mathrm{T}}$ and Saccharothrix longispora NRRL B$16116^{\mathrm{T}}$, for which sequence information had been previously reported (Warwick et al., 1994) as well as Saccharothrix species NRRL B-16108 and NRRL B16133.

The phylogenetic dendrogram shown in Fig. 1 was derived from evolutionary distances by the neighbourjoining method. A total of 1384 nucleotides between positions 99 and 1440 (Escherichia coli numbering; Brosius et al., 1978) were used for the analysis. Phylogenetic analyses using maximum-likelihood and parsimony methods generated very similar results and are not shown.

\section{DISCUSSION}

\section{Intrageneric structure of the genus Saccharothrix}

The intrageneric relationship among the species of Saccharothrix in this study based on 16S rDNA sequences, as seen in Fig. 1, is somewhat surprising since the genus appears phylogenetically heterogeneous. On the basis of the phylogenetic relationships observed in this study, Saccharothrix sensu stricto would appear to consist of Saccharothrix australiensis NRRL $11239^{\mathrm{T}}$ (the type species), Saccharothrix coeruleofusca NRRL B-16115 $5^{\mathrm{T}}$, Saccharothrix espanaensis NRRL $15764^{\mathrm{T}}$, Saccharothrix longispora NRRL B$16116^{\mathrm{T}}$, Saccharothrix mutabilis subsp. capreolus DSM $40225^{\mathrm{T}}$, Saccharothrix mutabilis subsp. mutabilis DSM $43853^{\mathrm{T}}$, Saccharothrix syringae NRRL B-16468 ${ }^{\mathrm{T}}$ and Saccharothrix texasensis NRRL B-16134 ${ }^{\mathrm{T}}$, as well as the unnamed Saccharothrix strains NRRL B-16108 and NRRL B-16133. The strains of Saccharothrix texasensis sequenced, NRRL B-16107 and NRRL B$16134^{\mathrm{T}}$, were previously shown to have $89 \%$ DNA relatedness and not surprisingly had $100 \%$ agreement in their 16S rDNA sequences. Saccharothrix waywayandensis NRRL B-16159 $9^{\mathrm{T}}$ appears to be phylogenetically more closely related to 'Asiosporangium albidum' IFO 16102 and Lentzea albidocapillatus DSM $44073^{\mathrm{T}}$ than the other Saccharothrix species, while Saccharothrix aerocolonigenes NRRL B-3298 ${ }^{\mathrm{T}}$, Saccharothrix flava NRRL B-16131 ${ }^{\mathrm{T}}$ and Saccharothrix cryophilis NRRL B-16238 ${ }^{\mathrm{T}}$ do not seem to belong to Saccharothrix or any other described actinomycete genus. The latter strain, however, appears be more related to the sporangiate genera 'Actinoalloteichus', Streptoalloteichus or Kutzneria. The 16S rDNA sequence data do explain anomalies previously observed in DNA relatedness studies of the genus Saccharothrix (Labeda \& Lechevalier, 1989; Labeda \& Lyons, 1989) where strains NRRL B-3298 ${ }^{\mathrm{T}}$, NRRL B-16159 ${ }^{\mathrm{T}}$ and NRRL B-16238 ${ }^{\mathrm{T}}$ exhibited extremely low DNA relatedness $(<20 \%)$ to any of the other Saccharothrix strains. DNA relatedness values below $20 \%$ observed between strains could be interpreted as indicating that they belong to different genera, but in the case of the aforementioned Saccharothrix strains, the chemotaxonomic and morphological properties observed placed them within the description for the genus Saccharothrix.

\section{Phylogenetic relationship of the genus Saccharothrix and related genera with the other actinomycetes}

Although it has been suggested in the past (Embley et al., 1988; Warwick et al., 1994) that the genus Saccharothrix should be placed in the family Pseudonocardiaceae, the phylogenetic position of the genus Saccharothrix and the allied genera Actinokineospora, Actinosynnema and Lentzea relative to the genera representative of other actinomycete families was consistent and distinct from the Pseudonocardiaceae, as can be seen in Fig. 1, regardless of phylogenetic analysis methods used. The relationship of this clade 


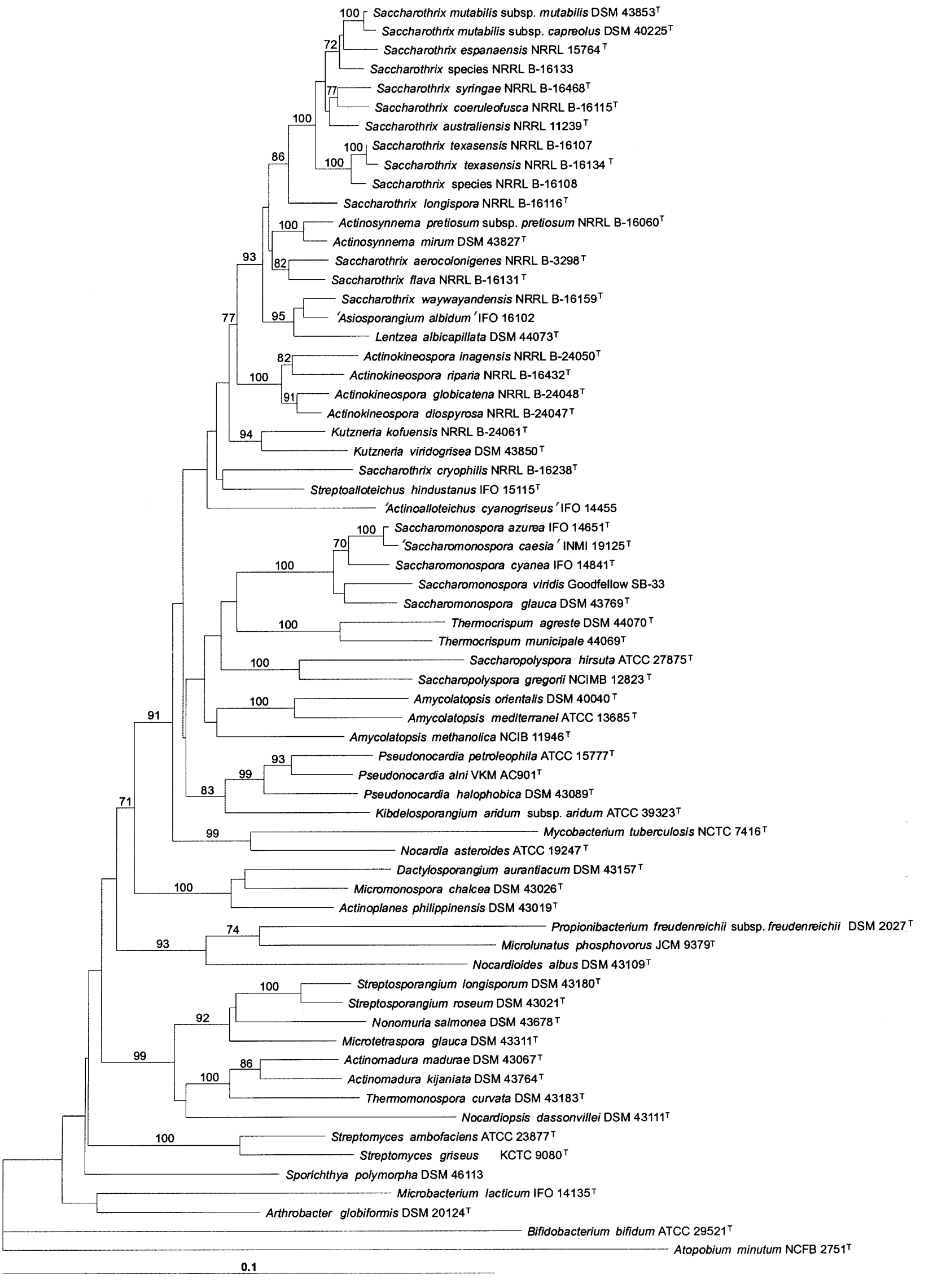

Fig. 1. For legend see facing page. 
Table 2. Chemotaxonomic characteristics of members of the proposed family Actinosynnemataceae and related genera

For all genera, the cell wall diamino acid was meso-DAP and the cell wall chemotype was III.

\begin{tabular}{|c|c|c|c|c|c|}
\hline Taxon & Whole-cell sugar pattern & $\begin{array}{l}\text { Phospholipid } \\
\text { type }\end{array}$ & Phospholipid* & $\begin{array}{l}\text { Predominant } \\
\text { menaquinone }\end{array}$ & Fatty acid \\
\hline 'Actinoalloteichus' $\dagger$ & Ribose, mannose, galactose & PII & PME & $\begin{array}{c}\text { MK- } 9\left(\mathrm{H}_{4}\right), \text { MK- } 8\left(\mathrm{H}_{4}\right) \\
\text { MK- } 9\left(\mathrm{H}_{2}\right)\end{array}$ & iso, anteiso \\
\hline Actinokineospora & Galactose, mannose, rhamnose & PII & $\mathrm{PE}$ & MK-9( $\left(\mathrm{H}_{4}\right)$ & Straight-chain, monounsaturated, iso, anteiso \\
\hline Actinosynnema & Galactose, mannose & PII & PE, PI, PIM, DPG & MK-9 $\left(\mathrm{H}_{4}\right)$, MK-9 $\left.-\mathrm{H}_{6}\right)$ & Straight-chain, monounsaturated, anteiso \\
\hline 'Asiosporangium' $\$$ & Arabinose, xylose & ND & ND & ND & ND \\
\hline Kutzneria§ & Trace, galactose, rhamnose & PII & PE, DPG, PG, PI & MK- $9\left(\mathrm{H}_{4}\right)$ & Straight-chain, unsaturated, iso, anteiso \\
\hline Lentzea & Galactose & PII & PE, DPG, PG, PI & MK-9 $\left(\mathrm{H}_{4}\right)$ & Straight-chain, monounsaturated, iso, anteiso \\
\hline Saccharothrix & Galactose, rhamnose, mannose & PII, PIV & PE, PIM, PI, DPG, PG & MK-10 $\left(\mathrm{H}_{4}\right)$, MK-9 $\left(\mathrm{H}_{4}\right)$ & Straight-chain, monounsaturated, iso, anteiso \\
\hline Streptoalloteichus & Galactose, mannose, rhamnose & PII & $\mathrm{PE}$ & MK-9 $\left(\mathrm{H}_{6}\right)$, MK-10( $\left.\mathrm{H}_{6}\right)$ & $\mathrm{ND}$ \\
\hline
\end{tabular}

ND, Not determined.

* DPG, diphosphatidyl glycerol; PE, phosphatidyl ethanolamine; PG, phosphatidyl glycerol; PI = phosphatidyl inositol; PIM = phosphatidyl inositol mannosides; PME, phosphatidyl methylethanolamine.

$\dagger$ Data from Itoh et al. (1987).

+ Data from Tamura \& Hatano (1998).

$\S$ Data from Stackebrandt et al. (1994).

to the other actinomycete families studied, including the Pseudonocardiaceae, is supported by a bootstrap value of $77 \%$ and provides good evidence for the creation of a new family for these genera. The relationship to the Pseudonocardioaceae was consistent for all phylogenetic analysis methods used. The levels of $16 \mathrm{~S}$ rDNA sequence similarity between the taxa in the proposed new family and the members of other actinomycete lineages were $100-95 \cdot 1 \%$ and $93 \cdot 4$ $79 \cdot 1 \%$, respectively. A diagnostic nucleotide signature pattern of TA (823-975), GC (824-874) was also observed for all of the strains proposed for inclusion into the family Actinosynnemataceae.

The phylogenetic position of Kutzneria kofuensis, Kutzneria viridogrisea, Streptoalloteichus hindustanus, Saccharothrix cryophilis and 'Actinoalloteichus cyanogriseus' is not clear at this time. These sporangiate taxa have the appropriate chemotaxonomic profiles (i.e. meso-DAP, galactose and possibly rhamnose and mannose as diagnostic sugars, PII phospholipid pattern, and menaquinones with nine isoprenoid units) and exhibit $16 \mathrm{~S}$ rDNA sequence similarities ranging from $96 \cdot 1$ to $92 \cdot 1 \%$ with the taxa in the proposed new family, but the low bootstrap values observed do not support inclusion of these taxa into the Actinosynnemataceae and they also do not have the nucleotide signature pattern observed for the family. Saccharothrix cryophilis NRRL B-16238 was recently observed to produce sporangia, and thus all of these related genera produce sporangia. Maximum-parsimony analysis of the data implied a close relationship of these genera with the Pseudonocardiaceae, while the other algorithms used demonstrated linkage with the
Actinosynnemataceae. It is likely that these taxa represent a new lineage separate from either family, but this probably can only be clarified by isolating additional representatives and sequencing their $16 \mathrm{~S}$ rDNA.

An evaluation of the chemotaxonomic characteristics reported in the descriptive literature for all of these genera, seen in Table 2, also supports the creation of a new family, since these genera have cell wall type III (meso-DAP), all have galactose in their whole-cell sugar pattern, most have mannose and/or rhamnose, phosphatidylethanolamine is a common constituent of the phospholipid pattern (type PII), and all contain menaquinones with nine isoprenoid units (MK-9). It is proposed that this family be named the Actinosynnemataceae for the oldest named genus in the family, Actinosynnema Hasegawa, Lechevalier and Lechevalier 1978 (Hasegawa et al., 1978). A formal description of the family follows:

\section{Description of Actinosynnemataceae fam. nov. Labeda and Kroppenstedt}

Actinosynnemataceae (Ac.ti.no.syn.ne.mat'ace.ae. M.L. n. Actinosynnema type genus of the family, pl. Actinosynnemata; L. ending -ceae ending to denote a family; M.L. n. Actinosynnemataceae the Actinosynnema family).

Aerobic, catalase-positive actinomycetes comprising the genera Actinokineospora, Actinosynnema, Lentzea and Saccharothrix. Vegetative mycelium branches, diameter approximately $0 \cdot 5-0 \cdot 7 \mu \mathrm{m}$; aerial mycelium

Fig. 1. Phylogenetic dendrogram reconstructed from evolutionary distances (Kimura, 1980) by the neighbour-joining method (Saitou \& Nei, 1987), indicating the position of members of the family Actinosynnemataceae compared to the family Pseudonocardiaceae and representatives of the main lineages of the order Actinomycetales. Bar, $0 \cdot 1$ nucleotide substitutions per site. 
is produced and fragments into chains of smoothsurfaced, rod-shaped elements which may be motile. Synnemata or dome-like bodies may be also be formed on the agar surface. Vegetative mycelium may also fragment into coccoidal rod-shaped elements. Grampositive. Not acid-fast. Resistant to lysozyme. Soils and plant materials are typical habitats. The genera from a coherent phylogenetic unit on the basis of partial 16S rDNA sequences. Type III cell wall composition (meso-diaminopimelic acid). Whole-cell sugars pattern consists of galactose and may also include rhamnose and mannose. Phospholipid pattern is type PII with a significant amount of phosphatidylethanolamine. The principal menaquinone consists of nine isoprenoid units (MK-9), although the degree of unsaturation may vary. The $\mathrm{G}+\mathrm{C}$ content of the DNA ranges from 68 to $76 \mathrm{~mol} \%$.

\section{ACKNOWLEDGEMENTS}

The able technical assistance of E. N. Hoekstra in the isolation and purification of DNA, PCR amplification of $16 \mathrm{~S}$ rDNA, and sequence determinations for this study is gratefully acknowledged.

\section{REFERENCES}

Brosius, J., Palmer, M. L., Kennedy, J. P. \& Noller, H. F. (1978). Complete nucleotide sequence of a $16 \mathrm{~S}$ ribosomal RNA gene from Escherichia coli. Proc Natl Acad Sci USA 75, 4801-4808.

Cote, R., Daggett, P.-M., Gantt, M. J., Hay, R., Hay, S.-C. \& Pienta, P. (1984). ATCC Media Handbook. Rockville, MD: American Type Culture Collection.

Embley, M. T., Smida, J. \& Stackebrandt, E. (1988). The phylogeny of mycolate-less wall chemotype IV actinomycetes and description of Pseudonocardiaceae fam. nov. Syst Appl Microbiol 11, 44-52.

Felsenstein, J. (1993). PHYLIP (phylogenetic inference package) version 3.5. Department of Genetics, University of Washington, Seattle.

Grund, E. \& Kroppenstedt, R. M. (1989). Transfer of five Nocardiopsis species to the genus Saccharothrix Labeda et al. 1984. Syst Appl Microbiol 12, 267-274.

Hasegawa, T., Lechevalier, M. P. \& Lechevalier, H. A. (1978). A new genus of the Actinomycetales, Actinosynnema gen. nov. Int J Syst Bacteriol 28, 304-310.

Itoh, T., Kudo, T. \& Seino, A. (1987). Chemotaxonomic studies on new genera of actinomycetes proposed in Chinese papers. Actinomycetologica 1, 43-59.

Kimura, M. (1980). A simple method for estimating evolutionary rates of base substitutions through comparative studies of nucleotide sequences. J Mol Evol 16, 111-120.

Labeda, D. P. \& Lechevalier, M. P. (1989). Amendment of the genus Saccharothrix Labeda et al. 1984 and descriptions of Saccharothrix espanensis sp. nov., Saccharothrix cryophilus sp. nov., and Saccharothrix mutabilis comb. nov. Int $J$ Syst Bacteriol 39, 419-423.

Labeda, D. P. \& Lyons, A. J. (1989). Saccharothrix texasensis sp. nov. and Saccharothrix waywayandensis sp. nov. Int J Syst Bacteriol 39, 355-358.

Labeda, D. P., Testa, R. T., Lechevalier, M. P. \& Lechevalier, H. A. (1984). Saccharothrix: a new genus of the Actinomycetales related to Nocardiopsis. Int J Syst Bacteriol 34, 426-431.

Maidak, B. L., Larsen, N., McCaughey, M. J., Overbeek, R., Olsen, G. J., Fogel, K., Blandy, J. \& Woese, C. R. (1994). The Ribosomal Database Project. Nucleic Acids Res 22, 3485-3487.

Olsen, G. J., Matsuda, H., Hagstrom, R. \& Overbeek, R. (1994). fastDNAml: a tool for construction of phylogenetic trees of DNA sequences using maximum likelihood. CABIOS 10, 41-48.

Page, R. D. M. (1996). TREEVIEW: an application to display phylogenetic trees on personal computers. CABIOS 12, 357358.

Rainey, F. A., Ward-Rainey, N. L., Kroppenstedt, R. M. \& Stackebrandt, E. (1996). The genus Nocardiopsis represents a phylogenetically coherent taxon and a distinct actinomycete lineage: proposal of Nocardiopsaceae fam. nov. Int J Syst Bacteriol 46, 1088-1092.

Saitou, N. \& Nei, M. (1987). The neighbor-joining method: a new method for reconstructing phylogenetic trees. Mol Biol Evol 4, 406-425.

Stackebrandt, E., Kroppenstedt, R. M., Jahnke, K.-D., Kemmerling, C. \& Gürtler, H. (1994). Transfer of Streptosporangium viridogriseum (Okuda et al. 1966), Streptosporangium viridogriseum subsp. kofuense, and Streptosporangium albidum (Furumai et al. 1968) to Kutzneria gen. nov. as Kutzneria viridogrisea comb. nov., Kutzneria kofuensis comb. nov., and Kutzneria albida comb. nov., respectively, and emendation of the genus Streptosporangium. Int J Syst Bacteriol 44, 265-269.

Stackebrandt, E., Rainey, F. A. \& Ward-Rainey, N. L. (1997). Proposal for a new hierarchic classification system, Actinobacteria classis nov. Int J Syst Bacteriol 47, 479-491.

Swofford, D. L. (1993). PAUP: phylogenetic analysis using parsimony, version 3.1. In Natural History Survey. Champaign, IL: Illinois Natural History Survey.

Tamura, T. \& Hatano, K. (1998). Phylogenetic analyses on the strains belonging to invalidated genera of the order Actinomycetales. Actinomycetologica 12, 15-28.

Warwick, S., Bowen, T., McVeigh, H. \& Embley, T. M. (1994). A phylogenetic analysis of the family Pseudonocardiaceae and the genera Actinokineospora and Saccharothrix with 16S rRNA sequences and proposal to combine the genera Amycolata and Pseudonocardia in an emended genus Pseudonocardia. Int J Syst Bacteriol 44, 293-302.

Yassin, A. F., Rainey, F. A., Brzenzinka, H., Jahnke, K.-D., Wessbrodt, H., Budzikiewicz, H., Stackebrandt, E. \& Schaal, K. P. (1995). Lentzea gen. nov., a new genus of the order Actinomycetales. Int J Syst Bacteriol 45, 357-363. 